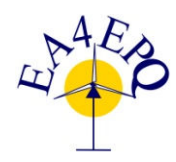

International Conference on Renewable Energies and Power Quality (ICREPQ'13)

Bilbao (Spain), 20 ${ }^{\text {th }}$ to $22^{\text {th }}$ March, 2013

Renewable Energy and Paver Quality. Fournal (RE\&PQJ)

ISSN 2172-038 X, No.11, March 2013

\title{
Efficiency Evaluation Of Filters Applied In Thermoeletrics From The Analysis Of Process Variables.
}

\author{
Neto, J. M. ${ }^{1}$, Pauletti, F. ${ }^{2}$, Ando Junior, O. H. ${ }^{1}$, Spacek, A. D. ${ }^{1}$, Oliveira, M. O. ${ }^{2}$, Schaeffer, L. ${ }^{2}$ and Bretas, A. S. ${ }^{2}$ \\ ${ }^{1}$ Department of Electrical Engineering \\ SATC, Beneficent Association of Santa Catarina Coal Industry \\ Pascoal Meller Street, 73. Criciúma-Sc (Brazil) \\ Phone/Fax number: +55 48 3431-75.50, e-mail: joao.neto@satc.edu.br, oswaldo.junior@satc.edu.br, \\ anderson.spacek@satc.edu.br \\ ${ }^{2}$ School of Engineering \\ UFRGS, Federal University of Rio Grande do Sul \\ Av. Osvaldo Aranha, 103. Porto Alegre-Rs (Brazil) \\ Phone/Fax number: +55 51 3308-31.29, e-mail: pauletti@ @hotmail.com, moliveira@ece.ufrgs.br, schaefer@ufrgs.br, \\ abretas@ece.ufrgs.br
}

\begin{abstract}
.
The generation of energy for thermoelectric has the benefit of not relying on environmental situations, as in the case of hydropower that can be influenced by the effects of weathering on the high or low level of its water reservoirs. However, the thermoelectric plants can bring harm to the environment by the emission of particulate material into the atmosphere. Filters of various principles can be used for containment of those fly ashes, as the cyclone filter. Given the relatively low costs involved this is widely used in a industrial scale and, for having a greater scope for gains in efficiency, will be addressed during this exposed. Is this article, it's contemplated the study of the influence of the system's variables, such as flow velocity of the gas inlet and the diameter of the particles suspended therein. It must be said that this study aims to technical study the filter, not normally considered the economic feasibility of possible changes and implementations; as such factors may serve as a disincentive to finding new methods and technology, which, since then, must be evaluated economically.
\end{abstract}

Keywords: filter cyclone, particle diameter, flow velocity.

\section{Introduction}

The countries in economic growth have in common the need for energy resources as a basis for increasing the productive sector. Sustainable development is a relevant factor in the analysis of growth, minimizing the environmental impact that man has on the planet.

Brazil, following this scenario, has a National Energy Plan. PNE 2030, which aims to diversify the national energetic matrix by the year 2030. According to the
Ministry of Mines e Energy, the electricity from coal accounted, in $2005,1.8 \%$ of the national energetic matrix, however, by the plans of the PNE, the share of coal in the national energetic matrix, in 2023, will increase to $5.35 \%$. [1] However the main obstacle to increasing the share of coal in the national energetic matrix is due to the fact that today most of the countries makes the power generation through direct combustion of the fuel. This process generates high amounts of greenhouse gases, which contribute to global warming. Coal will still be widely used for electric power generation, considering its low price, high availability and distribution of this fuel. [2] According to the industry report of Ciecesc (2008), firms belonging to the coal basin of south Santa Catarina produced 2.6 million tons of coal in 2007. A big part of that whole, about $90 \%$ was destined for power generations in thermal Jorge Lacerda in Capivari de Baixo - SC (857MW). These miners generate 4 thousands of direct jobs and about 40 thousands of indirect jobs, standing out as one of the most important sectors for the regional and national economy and is considered a cornerstone of economic development. [3] Due to technical limitations of existing boilers and environmental laws, the different types of coal used in thermal generation's process must satisfy certain criteria physicochemical. This implies in high costs for mining companies that supply raw materials, causing all measures that generate increase in efficiency and cost savings in other areas of interest are welcome.

In thermoelectric plants of coal generation, the capture of solid waste from the combustion of fuel usually happens through the use of systems cyclones, electrostatic precipitation or bag filter. These controllers emissions are, in general, efficient, especially in ration gas of input/output. However, it is a study indicating which 
parameters can be modified aiming to use the minimum necessary energy, according to the characteristic momentary gas to be filtered, which provides a more efficient process, lower energy consumption and increases the life of the equipment itself.

It is intended to analyze the efficiency of filters according to the characteristic of the material. Thus, the development of the theme will be returned to the industry of thermoelectric energy generation, specifically in the equipment to reduce greenhouse gas emissions from heat generation system.

\section{FILTER MODELS}

According to Marreco et al (2006), common measures to perform the filtering gases in Brazilian industry, whether for electricity production or other processes involving emission of particulates, atomization of slurry to the ceramic industry, grain industry, cement and feed, are:[4]

- Cyclones for separating particles having different densities;

- Gas scrubbers for adsorption of water with solid particles and subsequent decantation;

- Bag filter for particulate adherence to certain types of fibers;

- Eletrostatic precipitators, whose operating principle of ionization of fine particles, so that these are retained by adherence to an electrically charged plate. As used in Themoeletric Jorge Lacerda - Capivari de Baixo - SC and, according to Darcovich (1997), is the most effective way of action on fine particles. [5]

- Hybrid Precipitator: Advanced Hybrid Particulate Collector - CHAP. According to Miller (2000), this equipment uses the data collection as the electrostatic filtering sleeves in a single configuration for removal of particulates from a stream of exhaust air. It incorporates high particle collection with a smaller area compared to the methods of conventional particulate controls. Remains as a great promise as being a relatively inexpensive method of preventing air pollution from the energy production systems. [6]

\section{FILTER ANALYSIS}

To make an analysis of the efficiency of filters for thermoelectric, a study may have two lines: one that checks the results observed by cold clean air outlet in relation to the incoming flow in the filter or, another, which checks not only the result numerical equipment, but rather, all that evaluates a context since the method of construction, durability and past the costs and also maintenance and operability thereof. The same goes for choosing which filter should be installed in an industry, linking its installation cost, efficiency, maintenance costs and operating costs. The table I illustrates a relationship that takes into account the factors described:
Table I. - Relationship of efficiency, particle sizes retained and costs relating to different types of filters. [7]

\begin{tabular}{|c|c|c|c|}
\hline Parameter & Cyclone & $\begin{array}{c}\text { Precipitator } \\
\text { Electrostatic }\end{array}$ & Sleeves filters \\
\hline Efficiency & 70 to $90 \%$ & $\begin{array}{c}\text { Upper to } \\
98 \%\end{array}$ & $\begin{array}{c}\text { Upper to } \\
99,99 \%\end{array}$ \\
\hline $\begin{array}{c}\text { Particle } \\
\text { retained }\end{array}$ & $\begin{array}{c}\text { Bigger than } \\
10 \mu \mathrm{m}\end{array}$ & $\begin{array}{c}\text { Bigger than } \\
0,001 \mu \mathrm{m}\end{array}$ & $\begin{array}{c}\text { Bigger than } \\
0,1 \mu \mathrm{m}\end{array}$ \\
\hline $\begin{array}{c}\text { Cost of } \\
\text { investment }\end{array}$ & Low & High & Medium \\
\hline $\begin{array}{c}\text { Cost of } \\
\text { maintenance }\end{array}$ & Low & High & Medium \\
\hline $\begin{array}{c}\text { Cost of } \\
\text { operation }\end{array}$ & Low & High & Low \\
\hline
\end{tabular}

It is observed in Table 1 that both the exposed fabric filter and the electrostatic precipitator works on tracks very close to the ideal, in other words, $100 \%$ of efficiency in air purification, whereas the cyclone filter still has a relatively high margin of possibilities for increasing the efficiency.

Generally, the separation efficiency in a system of order 0 to $70 \%$ is not always the same as that traverses to change its result from 70 to $100 \%$. In similar terms says that it much easier to change 10 percentage points when it is at an intermediate level, in other words, up to $70 \%$, than a 1 percentage point change to pass a system that, for example, work with $98 \%$, to $99 \%$.

\subsection{Determination of Filter to analyze}

As table I shows, the costs of installation, maintenance and operation of the filter cyclone show up lower against the other technologies, making it of great interest to industrial plants or smaller ones or, as the governing rules of capitalism to companies seeking to lower expenses. Glimpsing the above yet, we chose to study the determination of the cyclone filter, in order to provide and analysis on the value of efficiency in parallel with no significant change in its costs considered exposed. For this, one needs to make a mathematical model to obtain the equipment which variables influence the process. Thus it will permit mathematical modeling of the filter and, lastly, will propose means of evaluation were previously studied which act to ensure a considerable increase of the quality of the output air to atmosphere.

Several factors can influence the efficiency of the cyclone filter, which are: the speed of air flow, the particle size and the nature of these powder, sand, coal ashes, etc. The internal diameter of the filter and moisture gas. However, in industrial processes, not all variables can be demonstrated explored as a means of correcting and increasing efficiency, as the diameter of equipment which, once constructed, becomes fixed over time. The level of particulate concentration depends on the nature and conditions of the combustion performed and therefore generally cannot be controlled.

The speed of the air current that runs through the filter is critical to be analyzed, for speeds above the ideal causes excessive abrasion to the sides of the machine, wearing it and carrying a portion of the particles that were unable to settle, due to the effect and high volume of airflow. 
Conversely, low velocities entail a large loss of load on the system, which in many cases its not convenient.

It remains so, considering the diameter of the particles present in the gas stream inlet, the volume, moisture, temperature, and internal dimensions of the filter, for possible actions in the flow velocity, according to a constructive considered the same. According to Koch and Licht (1980), the simple construction, low power consumption and capability for operation at high pressures and temperatures, makes the filter cyclone widely used in industry. The operation and maintenance of low complexity when compared to other types of filters corroborate this assertion. [8]

Justifies the use of a filter Cyclone considering its efficiency and pressure drop. These parameters are mainly studied in the design and operation of the equipment.

\subsubsection{Analysis of direct relationship between particle diameter and flow velocity}

To make a direct relationship between speed and particle diameter makes the analysis in two steps, the first by adopting a fixed speed and varying the particle size and the second, the reverse. Thus, initially adopted, for criteria wide use in practice, the fixed speed of the flow at $10 \mathrm{~m} / \mathrm{s}$, so the variation of the particle diameter, the values of 0.25 , $0.5,1,1,5,3,5,10$, and $30 \mu \mathrm{m}$.

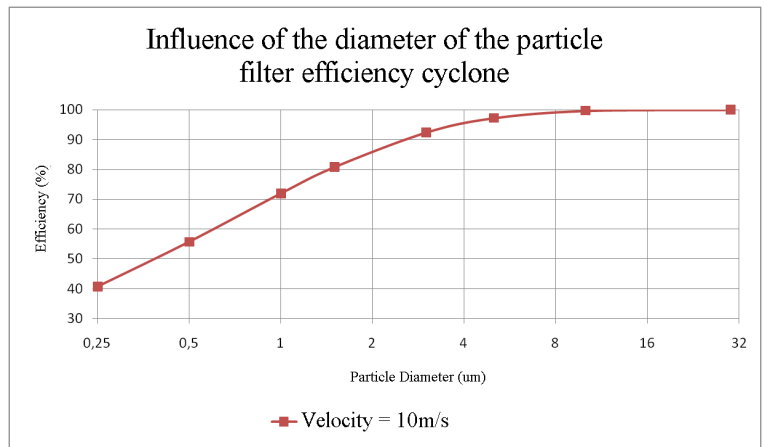

Figure 1 - The influence of the particle diameter in efficiency weight.

It is observed in Figure 1 that for particles larger than $10 \mu \mathrm{m}$, its result is almost constant, leaving efficiencies around $99 \%$. To evaluate the direct influence on the efficiency weight felt by speed variation, adopted as fixed diameter $5 \mu \mathrm{m}$, criteria for target of interest for study, whereas for larger diameters this type of filter has already found satisfactory efficiency.

The velocity values that were tested are: $0.5,1,2,3,5,7$, 10 and $15 \mathrm{~m} / \mathrm{s}$, to obey the usual level of work in practice. The results appear in the graph of Figure 2. In this you can see that the speed influences the response of filter efficiency cyclone. With the numerical results, it can be stated, for a fixed diameter of particle, in the example $5 \mu \mathrm{m}$, the velocity reaches a maximum threshold which offers no further gain in efficiency of the filter, this being after the value of $15 \mathrm{~m} / \mathrm{s}$. With this analysis it is possible to predict how the system behaves against the action of the speed variation, which provides a larger range to study how to verify the modeling system.

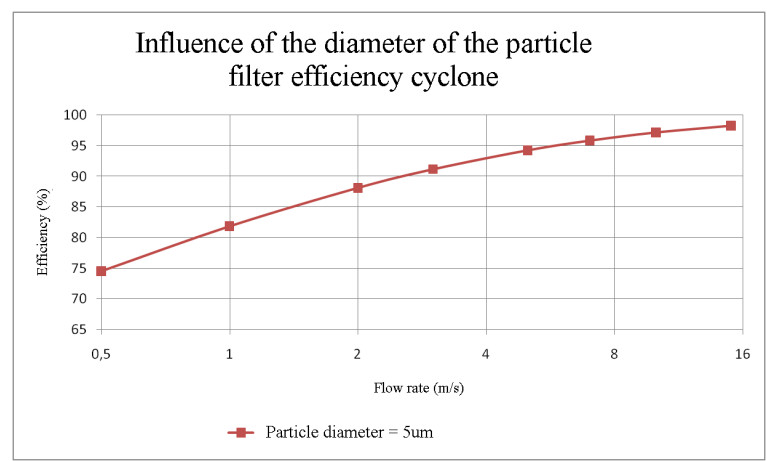

Figure. 2 - Graph of the variation of the flow velocity efficiency weight.

Thereafter, it is for values of velocity and particle diameter tested a mathematical arrangement for testing all possible combinations. For example, find the values of efficiency, using $0.5 \mathrm{~m} / \mathrm{s}$ and $0.25 \mu \mathrm{M}$, then use $0.5 \mathrm{~m} / \mathrm{s}$ and $0.5 \mu \mathrm{m}$ and so for the others.

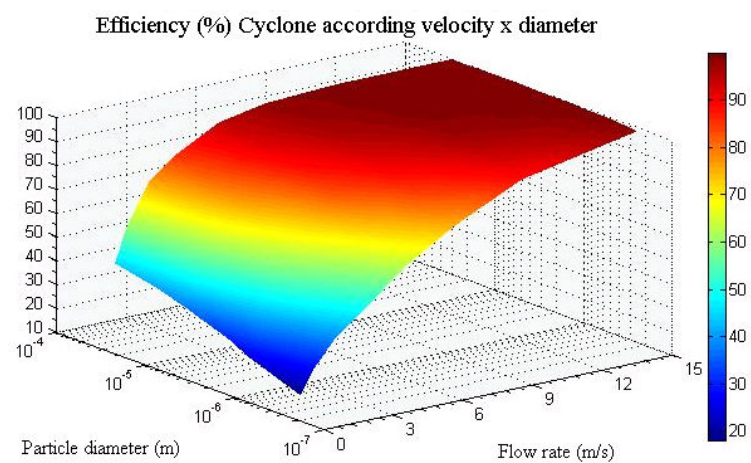

Figure 3 - 3D graph - Efficiency of the cyclones due speed $\mathrm{x}$ diameter particles.

Through this analysis it is possible to note that in systems with particle diameter known and relatively constant, one can determine the lowest working speed which provides the highest efficiency, providing lower energy costs and maintenance of the machinery responsible for ventilation of air flow to cyclone. In the possibility of a particle size analyzer in real time, it is possible to vary the speed according to the input diameter, providing a increased efficiency possible by weight.

In another analysis, takes up work as a minimum basis for criteria common goal of practical use, the value of efficiency in the order of $90 \%$. The graph shown in Figure 4 expresses, for the established efficiency, the ratio of input speed as a function of particle diameter.

With this analysis, it is possible to provide for the appropriate speed depending on the variations of the incoming particulate efficiency to keep the acceptable level of $90 \%$. 
Velocity variation as a function of particle diameter

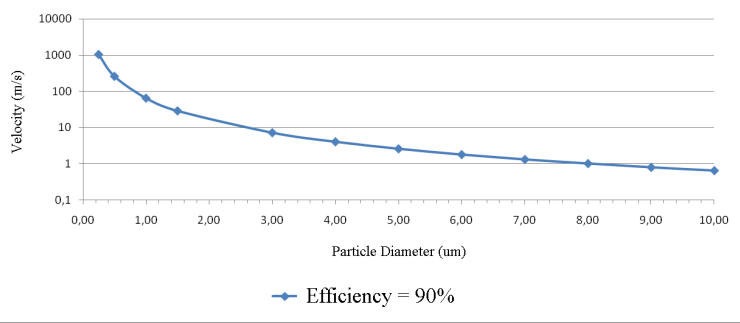

Figure 4 - Speed in function of particle diameter for efficiency in $90 \%$.

\section{FINAL CONSIDERATIONS}

Cyclone Filters are equipments for cleaning a stream of exhaust air at a cost relatively lower than other types of filters, but with questionable levels of efficiency and control nontrivial. The present study aimed to investigate the behavior of the cyclone filter change front two important variables in the air handling system: flow velocity and diameter of the particulate.

The results of direct examination of the influence of the diameter of the particles in the filter efficiency shows a tendency to increase the second addition in the dimension parallel to the first, due to the fact particles having diameters larger than the largest mass particle size of less if deemed having the same density as provirus the same principle of burning coal. Being of greater weight, these particles to move further up in the cyclone lose high kinetic energy to suffer with, among other factors, the friction with the walls inside the centrifugal effect of the cyclone. Moreover, the finer particles are less that purpose, staying in suspension and are naturally expelled into the atmosphere, polluting the environment.

Making variations only the speed, keeping the diameter of the particles fixed, it was also observed that filter efficiency increases as the system experiences an addition in speed, greatly depending on the particles at high speeds collide directly with the walls of cyclone, losing the energy that would keep the suspension. However, the effect of high speeds not only brings advantages: the greater the required speed, higher power should be the driving machine, in case one motor coupled with a fan. This generates a higher installation cost, as major powers engines are more expensive.

Even with high speed relation, this factor causes excessive collisions of the flying particles with the walls of the cyclone, causing a greater friction between them and the filter. Based on practical data, this increased friction allows a significant reduction in equipment life and even demonstrating efficiency gains should be avoided.

Although not discussed in this paper out any real costs involved for the means of evaluation of the input material, equipment to vary the speed motors, maintenance, etc., the value of this work is the improvement and understanding of a widespread industrial equipment and widely discussed by several studies, after all, means of corrections and efficiencies may be analogous to other systems, always with the aim of reducing the aggressions made in half environment, providing better quality of life not only to neighboring communities thermoelectric plants, but in the medium and long term, the ecosystem of the globe. It is, finally, that the work presented goals and adjustments necessary for a cyclone filter that, once properly designed and monitored, can provide a longer life and massive efficiency.

\section{REFERENCES}

[1] MINISTRY OF MINES AND ENERGY. Plano Nacional de Energia 2030. Brasília: MME, 2007.

[2] MOTA NETO, João; KAMINSKI, Diogo. IGCC: uma alternativa para a utilização de carvão mineral brasileiro. Economia\&tecnologia, Curitiba, v. 7, n. , p.137-145, 01 ago. 2011.

[3] Sectoral Report 2008. Ciecesc. Criciúma 2008.

[4] MARRECO, Juliana de M.. PEREIRA JR, Amaro. TAVARES, Marina E.. Perspectivas para a geração termelétrica a carvão. Revista Brasileira de Energia, v. 12, n. 2. 2006.

[5] K.DARCOVICH, K.A JOANSSON, C .E .CAPES. Developments in the control of fine particulate air emissions. Advanced Powder Technol, v. 8, n. 3, p. 179-215. VSP and Society of Powder Technology, Japan 1997.

[6] MILLER, S.J.; OLDERBAK, M.R.; ZHUANG, Y. Advanced Hybrid Particulate Collector; The Advanced Hybrid Particulate Collector FieldTesting Results. U.S. Department of Energy Contract No. Energy \& Environmental Research Center: Grand Forks, ND, Dez 2000.

[7] REGO, E. E. Avaliação da viabilidade de um empreendimento de geração de energia hidrelétrica. São Paulo: Universidade de São Paulo. 129 p. Monografia, Bacharel em Ciências Econômicas.

[8] KOCH, W.H. e LICHT, W.. "New Design Approach Boosts Cyclone Efficiency”. Industrial Air Pollution. Engineering Magazine, p. 175-183. 1980.

[9] MASSARANI, Giulio. Desempenho de Ciclones e Hidrociclones. Cetem, Cnpq: Série Tecnologia Mineral, Rio de Janeiro, 14 pg, 1992. 